6. G. W. Mackey, Ergodic theory and virtual groups, Math. Ann. 166 (1966), 187-207. MR 34 \#1444.

7. W. Parry, Zero entropy of distal and related transformations, Topological Dynamics (Sympos., Colorado State Univ., Ft. Collins, Colo., 1967), Benjamin, New York, 1968, pp. 383-389. MR 38 \#2760.

8. A. Ramsay, Virtual groups and group actions, Advances in Math. 6 (1971), 253-322. MR 43 \#7590.

9. J. von Neumann, Zur Operatorenmethode in der klassichen Mechanik, Ann. of Math. 33 (1932), 587-642.

DEPARTMENT OF MATHEMATICS, HARVARD UNIVERSITY, CAMBRIDGE, MASSACHUSETTS 02138

\title{
CORRIGENDUM, VOLUME 80
}

G. I. Lehrer, Weil representations and cusp forms on unitary groups, pp. 11371141 .

In the section (§5) on applications of Theorem $A$ of [1], the statement of Corollary 2, p. 1140 is stronger than what is yielded by the argument outlined in the succeeding discussion.

It should be replaced by

Corollary 2. For $n$ odd, we have $\Sigma_{u \in R} J_{n}(u)=0$ for $R$ the unipotent radical of any proper parabolic subgroup of $U_{n}$. 